\title{
Allele- and parent-of-origin-specific effects on expression of the $K C N J 11$ gene: A candidate for meat tenderness in cattle
}

\author{
M.M. de Souza ${ }^{1}$, S.C.M. Niciura ${ }^{1,2}$, P.C. Tizioto ${ }^{2}$, A.M.G. Ibelli ${ }^{1,3}$, \\ G. Gasparin ${ }^{4}$, M.I.P. Rocha ${ }^{1}$, F.A. Bressani², W. Malagó-Jr², W.J.S. Diniz ${ }^{1}$, \\ P.S.N. de Oliveira ${ }^{2}$, A.O. Lima1, M.A. Mudadu², W. Barioni Junior ${ }^{2}$, \\ L.L. Coutinho ${ }^{4}$ and L.C.A. Regitano ${ }^{1,2}$ \\ ${ }^{1}$ Departamento de Genética e Evolução, Universidade Federal de São Carlos, \\ São Carlos, SP, Brasil \\ ${ }^{2}$ Laboratório de Biotecnologia Animal, Embrapa Pecuária Sudeste, São Carlos, \\ SP, Brasil \\ ${ }^{3}$ Laboratório de Genética Animal, Embrapa Suínos e Aves, Concórdia, SC, Brasil \\ ${ }^{4}$ Departamento de Zootecnia, Escola Superior de Agricultura "Luiz de Queiroz", \\ Universidade de São Paulo, Piracicaba, SP, Brasil \\ Corresponding author: L.C.A. Regitano \\ E-mail: luciana.regitano@embrapa.br
}

Genet. Mol. Res. 15 (3): gmr.15038549

Received February 15, 2016

Accepted April 8, 2016

Published August 29, 2016

DOI http://dx.doi.org/10.4238/gmr.15038549

Copyright $(2016$ The Authors. This is an open-access article distributed under the terms of the Creative Commons Attribution ShareAlike (CC BY-SA) 4.0 License.

ABSTRACT. In contrast to the Mendelian inheritance model, parental alleles can contribute unequally to gene expression, which may result in phenotypic variance among individuals and bias in the predicted additive effect of molecular markers associated with production traits. Given the need to understand the effects of allelic variation and parentof-origin effects on the expression of genes with a commercial interest in cattle, we analyzed the expression of KCNJ11 (potassium inwardly 
rectifying channel, subfamily $\mathrm{J}$, member 11 ), which was previously described as a functional candidate gene for meat tenderness. Allelespecific and parent-of-origin-dependent expression of this gene were assessed in bovine muscle using the rs379610823 single nucleotide polymorphism as a reference. Biallelic expression was observed; however, the $\mathrm{T}$ allele was expressed at significantly higher levels than the $\mathrm{C}$ allele. Furthermore, increased expression of KCNJ11 was found in animals harboring the maternal $\mathrm{T}$ allele. This study is the first to describe the differential allelic expression of bovine KCNJ11. Our findings are important for understanding the mechanisms that underlie the pattern of KCNJ11 expression and its potential impact on the phenotypic variation of meat tenderness in Nelore beef cattle. This reinforces the need for further investigation of allelic- and parent-oforigin expression deviation in genetic markers eligible for the selection of target traits.

Key words: Differential allelic expression; Meat tenderness; Nelore; Potassium inwardly rectifying channel

\section{INTRODUCTION}

In addition to differences in DNA sequences and environment effects, mechanisms that regulate gene expression are relevant sources of variation among individuals. Despite the identical genetic constitution of each cell in an individual, tissue differentiation, and phenotypic variation occur during development, and these are regulated by the activation and inactivation of specific genes. Genomic predictions using molecular markers are modeled based on patterns of Mendelian inheritance, assuming that genes from maternal and paternal chromosomes contribute equally (i.e., are expressed equally), to the development of the offspring (Saupe, 2012). However, departures from this model occur, and the expression of some genes has been shown to be governed by unequal allelic contributions, which may bias such predictions.

Allele-specific expression (ASE) occurs throughout the mammalian genome (Tycko, 2010), may be a consequence of genetic and epigenetic mechanisms, and may have effects on phenotypic variation (Muráni et al., 2009; Tuch et al., 2010). The major genetic causes of ASE are polymorphisms in cis-regulatory sites. When allelic expression is governed by epigenetic events, such as DNA methylation, which result in allelic expression that is dependent on the parental origin of alleles, the pattern of expression is called genomic imprinting (Ruvinsky, 1999). Many studies have identified ASE and imprinting patterns for genes with important biological functions. For example, ASE has been consistently associated with cancer and disease-causing genes (Meyer et al., 2008; Simmer et al., 2012; Walker et al., 2012; Wei et al., 2013), such as Prader-Willi syndrome in humans (Wu et al., 2012). Subsequently, complex traits and diseases can be affected by genes displaying patterns of ASE, with or without parentof-origin effects (POE), and these expression patterns may result in phenotypic variation.

Despite the potential impact of ASE on complex traits, few genes with an allelic expression pattern have been described in cattle. A significant difference is observed when comparing the number of studied genes in human and mouse against livestock species in the

Genetics and Molecular Research 15 (3): gmr.15038549 
OTAGO database, which contains data on imprinted genes and their related effects (http://igc. otago.ac.nz/). Currently in this database, only 34 bovine genes have been found to be imprinted or non-imprinted whereas 332 and 228 entries exist for human and mouse, respectively. Since 2011, the number of records in the OTAGO database has changed, and while 14 new genes have been added for cattle, 90 entries have been added for human and mouse. The large difference observed between human and bovine imprinted genes reinforces the need to develop new studies aiming to describe the expression patterns of genes of interest in livestock. With the growing application of genomic selection in livestock, variation in the allelic expression of markers used in a single nucleotide polymorphism (SNP) panel could result in biased estimates of genomic value, and could subsequently affect genetic progress. The inclusion of direct markers in SNP panels, i.e., SNPs in genes that are expected to have a direct effect on the trait, has been proposed in order to increase the accuracy of prediction (Weller and Ron, 2011).

Among the production traits of interest, beef quality has gained a lot of attention, and meat tenderness is considered to be the most appreciated trait by global consumers (Verbeke et al., 2010). This trait is particularly relevant for Bos indicus breeds, such as Nelore, which are known to produce less tender meat. However, recent studies have shown that it has sufficient variability to be included in animal breeding programs (Tizioto et al., 2013a; Tonussi et al., 2015). In addition, it is a complex trait involving many genes, including KCNJ11 (potassium inwardly rectifying channel, subfamily J, member 11), which was recently associated with beef tenderness (Tizioto et al., 2013b). This gene plays a role in the insulin pathway, which induces glycogen storage in cells. Alekseev et al. (2010) showed that KCNJ11 knockout influenced muscle glycogen deposition and affected body fat in mice. Glycogen storage may affect meat tenderness because it influences the extension of glycolysis, which is the only source of ATP for cells following slaughter. The relationship between the rate and extension of glycolysis and meat tenderness has been shown in previous studies (Marsh et al., 1987).

The KCNJ11 gene is used as a molecular marker that can be introduced into bovine breeding programs for many reasons. First, KCNJ11 was located within a quantitative trait loci (QTL) for meat tenderness mapped to the bovine chromosome 15 (Rexroad et al., 2001). Second, this gene contains a SNP with additive effects estimated on meat tenderness (Tizioto et al., 2013b). Third, the expression profile of $K C N J 11$ also influences meat tenderness (Tizioto et al., 2013b). Finally, this gene accounts for some of the variability in muscle mass and lipid content (Bernard et al., 2009).

Although $K C N J 11$ variants are potential markers for incorporation in animal breeding programs, this gene has only been studied once in cattle. To date, the potential mechanisms that regulate $K C N J 11$ gene expression, such as ASE, have not been investigated in cattle. Thus, this study aimed to characterize the allelic expression of the bovine KCNJ11 gene and to verify whether this gene is imprinted. The description of KCNJ11 ASE may help to increase understanding on the regulation of its expression, provide information for estimating its real effects before incorporation in animal breeding programs, and may contribute to the description of imprinted genes in cattle.

\section{MATERIAL AND METHODS}

\section{Animals}

All animals were handled and managed according to the Institutional Animal Care and

Genetics and Molecular Research 15 (3): gmr.15038549 
Use Committee Guidelines, Brazilian Agricultural Research Corporation (EMBRAPA). Blood and muscle samples were obtained from 137 Nelore steers, which were raised and allocated in one feedlot located in São Carlos, Brazil. Eighteen unrelated bulls sired these steers.

\section{DNA and RNA extraction}

The DNA of 32 sires was extracted from semen purchased from Brazilian artificial insemination centers using a standard phenol-chloroform method (Sambrook et al., 1989). DNA was extracted from $5 \mathrm{~mL}$ blood from 137 steers using a salting-out method. The concentration and quality of DNA originating from semen and blood were analyzed by spectrophotometry (Eppendorf-Biophotometer ${ }^{\circledR}$, Orlando, FL, USA) and the integrity was assessed by agarose gel electrophoresis.

RNA was extracted from samples of longissimus dorsi muscle from the same steers, following the protocol described by Tizioto et al. (2013b). Muscle samples were collected at the time of slaughter, immediately frozen in liquid nitrogen, and kept at $-80^{\circ} \mathrm{C}$ until RNA extraction. Subsequently, $1 \mathrm{mg}$ total RNA from each sample was reverse transcribed to generate cDNA in $20-\mu \mathrm{L}$ reactions using an ImProm-II ${ }^{\mathrm{TM}}$ Reverse Transcription System kit (Promega). The cDNA was stored at $-20^{\circ} \mathrm{C}$ until use.

\section{Genotyping}

The SNP rs379610823, harbored in the 3' UTR region of KCNJ11, was used to evaluate the allelic expression of this gene in muscle samples of Nelore steers. Sire and steer genotypes were determined by real-time PCR TaqMan ${ }^{\circledR}$ assays (Applied Biosystem, Foster City, CA, USA), following the protocol described by the manufacturer. The primers 5'-CCCAGCCTGCTGGATGT-3' and 5'-CCACGGTGCGCTTGC-3' were used, as well as the TaqMan hydrolysis probes VIC-CCTGACCCTTGTCCGC, which recognizes the Tallele, and FAM-CTGACCCTCGTCCGC, which recognizes the $\mathrm{C}$ allele.

\section{ASE analysis}

Allele-specific qPCR was used to analyze ASE of KCNJ11 according to the method described by Lo et al. (2003), with cDNA derived from muscle and with the same hydrolysis probes used for genotyping. Considering that the performance of the two TaqMan ${ }^{\circledR}$ assay probes may differ during PCR, we built a standard linear regression curve to normalize these differences. A standard linear regression was constructed from serial dilutions of genomic DNA obtained from two homozygous individuals $(8: 1,4: 1,2: 1,1: 1,1: 2,1: 4,1: 8$; T allele/C allele). After 40 PCR cycles, the fluorescence intensity of each hydrolysis probe (VIC and FAM) was collected for each dilution (described above). From these data, we calculated the FAM/VIC intensity ratio and generated the standard curve.

The FAM/VIC intensity of each cDNA sample was also obtained after 40 cycles of PCR from the average of each triplicate. The allelic ratio for each sample was estimated by plotting the log FAM/VIC intensity average to the standard curve equation. To check whether the calculated $\mathrm{T} / \mathrm{C}$ allelic ratio was significantly different from 1, we applied the Student $t$-test, with a $95 \%$ confidence interval. Data normality was assessed by the ShapiroWilk test.

Genetics and Molecular Research 15 (3): gmr.15038549 


\section{Analysis of POE on total $K C N J 11$ gene expression}

Total KCNJ11 gene expression was determined by real-time PCR using the LightCycler $^{\circledR}$ detection system 480 (Roche). The reaction conditions and primers utilized have been previously described (Tizioto et al., 2013b). The amplification efficiencies were calculated using LinRegPCR (Ramakers et al., 2003), and differences in transcript frequency were calculated according to the method described by Livak and Schmittgen (2001). Next, we normalized the expression ratios using the ribosomal protein L19 (RPL-19; ID 510615) and eukaryotic elongation factor 1A (EEF1A; ID AJ238405.1) genes. A pairwise-fixed reallocation randomization test was used to test for significant differences at the $5 \%$ level in the Relative Expression Software Tool (REST; Pfaffl et al., 2002). To compare the expression among various genotypes, depending on parental origin, TC heterozygote animals for each SNP were separated into two groups according to allelic parental origin $(\mathrm{CmTp} \times \mathrm{CpTm}$; where $\mathrm{m}=$ maternal and $\mathrm{p}=$ paternal) as proposed by Garg et al. (2012) and compared in pairs using the REST software (Pfaffl et al., 2002).

\section{Transcription factor interaction site analysis}

Predicted transcription factor binding sites (TFBS) were obtained using the available database for bovine TFBS at http://199.133.54.77/BovineTFBS (Bickhart and Liu, 2013). Next, we checked whether any SNPs found at the first in silico analysis in KCNJ11 TFBSs are described in the public SNP database (http://www.ncbi.nlm.nih.gov/projects/SNP).

\section{RESULTS}

\section{Genotypes}

Seven samples of unknown genotype were excluded from the total population, leaving 130 genotyped individuals. Genotype analysis of 130 Nelore steers using hydrolysis probes in qPCR revealed that the genotype frequencies were similarly spread among each genotypic group (Table 1). Sires were genotyped to determine the parental origin of alleles (Table 1), and from the 42 steers that were heterozygous for the studied SNP, 30 had homozygous fathers. Next, we were able to separate the heterozygous samples into two genotypic groups based on their parental origin $\mathrm{CpTm}(\mathrm{N}=18)$ and $\mathrm{CmTp}(\mathrm{N}=12)$ (where $\mathrm{m}$ and $\mathrm{p}$ refer to the maternaland paternal-derived allele, respectively). These 30 samples were descended from five TT bulls and seven CC bulls. The remaining 12 heterozygous samples also had heterozygous fathers, which prevented the parental origin of the allele from being determined and were discarded from the subsequent analyses.

Table 1. KCNJ11 genotype frequencies for SNP rs379610823.

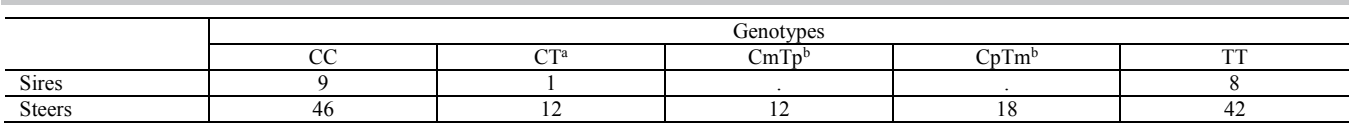

${ }^{a}$ Heterozygous with unknown parental origin. ${ }^{b} \mathrm{~m}=$ maternal origin of the allele; $\mathrm{p}=$ paternal origin of the allele.

Genetics and Molecular Research 15 (3): gmr.15038549 


\section{Analysis of ASE}

Of 30 heterozygous samples with known allele parental origin, 22 muscle samples were available for the ASE analysis using the SNP c.2342T $>$ C as a reference. Here, we found that all samples possessed higher expression of the $\mathrm{T}$ allele than of the $\mathrm{C}$ allele (Figure 1), with a mean ratio $\pm \mathrm{SD}$ of $1.495 \pm 0.184$ and confidence interval (Student's $t$-test, 95\%) of 1.4121.576. Considering that the expected ratio was $1: 1$, and that the values in the CI exceeded 1 , this indicates that despite the biallelic pattern of KCNJ11 expression, the $\mathrm{T}$ allele was expressed more frequently than the $\mathrm{C}$ allele, providing evidence of ASE in bovine muscle for the KCNJ11 gene.

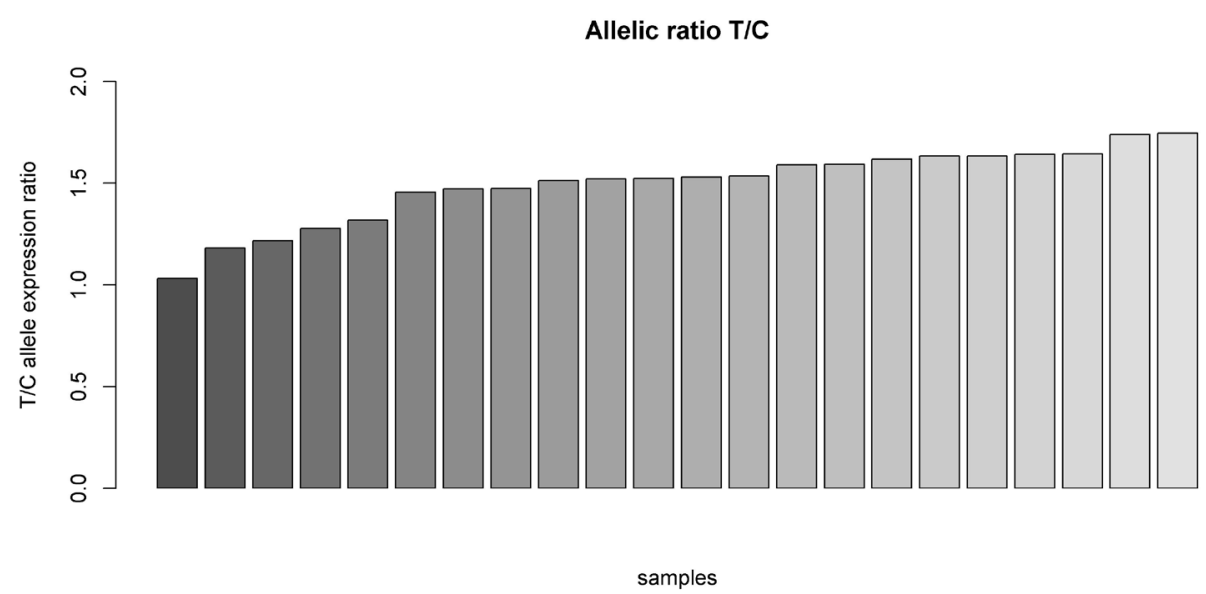

Figure 1. Ratio of T/C allele expression of SNP c.2342T $>\mathrm{C}$ the $K C N J 11$ gene in bovine muscle. Each bar represents one sample.

\section{Analysis of POEs on total $K C N J 11$ gene expression}

Total gene expression was analyzed to assess the influence of allelic parental origin on the overall expression of $K C N J 11$ in longissimus dorsi muscle. After normalization using housekeeping genes, we found that $K C N J 11$ gene expression was 0.47 -fold lower in the $\mathrm{TpCm}$ group $(\mathrm{N}=9)$ than in the TmCp group $(\mathrm{N}=17)$ when considering the parental origin of the SNP c.2342T $>$ C $(\mathrm{P}<0.05)$.

\section{Transcription factor interaction site analysis}

In total, 14 TFBSs were predicted (Table 2) in the KCNJ11 gene using the cattle database (Bickhart and Liu, 2013), but no SNPs described in the public SNP database were detected in these TFBSs in the KCNJ11 gene.

\section{DISCUSSION}

Few bovine genes have been described in terms of ASE and POEs on gene expression. 
Table 2. Localization of SNPs described in the putative KCNJ11 gene promoter region in the public SNP database NCBI, used for inspection of transcription factor binding sites alteration.

\begin{tabular}{l|c}
\hline SNP ID & Position (bp) \\
\hline $\mathrm{rs385951679}$ & $35,648,763$ \\
\hline $\mathrm{rs} 380643651$ & $35,648,793$ \\
\hline $\mathrm{rs} 384198080$ & $35,648,954$ \\
\hline $\mathrm{rs} 378579876$ & $35,649,020$ \\
\hline $\mathrm{rs} 37636247$ & $35,649,108$ \\
\hline $\mathrm{rs} 383472408$ & $35,649,121$ \\
\hline $\mathrm{rs} 41762280$ & $35,649,345$ \\
\hline $\mathrm{rs} 381203201$ & $35,649,702$ \\
\hline $\mathrm{rs} 383209175$ & $35,649,902$ \\
\hline $\mathrm{rs} 378423234$ & $35,649,920$ \\
\hline $\mathrm{rs} 41762281$ & $35,650,053$ \\
\hline $\mathrm{r} 384885814$ & $35,650,152$ \\
\hline
\end{tabular}

Thus, we provide evidence of ASE and POE of KCNJ11, which was previously identified as a candidate gene to improve meat tenderness (Tizioto et al., 2013b) in adult Nelore muscle tissue. Although this gene presents biallelic expression, we provide evidence of an ASE pattern resulting from higher expression of the $\mathrm{T}$ allele compared with the $\mathrm{C}$ allele. Furthermore, evidence of POE was found when the total expression of KCNJ11 was evaluated in muscle, with lower expression being observed in the heterozygous animals that received $\mathrm{T}$ allele from their fathers. Here, we add a new gene to the list of bovine genes for which allelic expression and POE is known. As far as we know, this is the first report of allelic expression patterns of the KCNJ11 bovine gene.

In our study, a SNP was used as a marker to distinguish transcripts from each allele in a heterozygous genotype; therefore, each allele acted as an internal control for the other (Lo et al., 2003; Yan and Zhou, 2004; Palacios et al., 2009). We found biallelic expression, which enables the hypothesis of a complete imprinting pattern in the muscle of Nelore steers to be discarded. In mammals, imprinted genes make up only $1 \%$ of known genes (Weaver et al., 2009), while ASE is common in non-imprinted loci throughout the genome (Tycko, 2010). Our results are consistent with those from other studies in humans (Locke et al., 2015), in which the KCNJ11 gene was found to be in allelic imbalance in beta cells. Even though this pattern is consistent between both species comparing different tissues, the observed pattern may vary within tissues and developmental stages.

Studies have shown that variation in allelic expression can be inherited in a Mendelian pattern (Pastinen and Hudson, 2004). In the case of KCNJ11, it is possible that the polymorphism analyzed is not the causal mutation affecting allelic expression. Therefore, it is presumably in linkage disequilibrium with one or more SNPs that lie within the promoter region, or another cis-acting regulatory element affecting TF binding (Tao et al., 2006; Panebra et al., 2007; 2010; Murani et al., 2013). Examples of these variations are given by SNPs used to analyze ASE of the beta-2 adrenergic receptor (ADRB2) gene in swine muscle (Muráni et al., 2009) and humans (Panebra et al., 2007), for which variation in allelic expression seems to be caused by multiple cis-regulatory polymorphisms in both species (Panebra et al., 2007; 2010; Murani et al., 2013). However, in the present study, none of the TFBSs found for the KCNJ11 gene were consistent with any SNPs already described in the literature. We cannot discard the possibility that polymorphic TFBSs explain ASE, since knowledge in this field is limited in cattle, and known TFs are specific for Bos taurus cattle. Another possible cause of ASE is the occurrence of polymorphisms

Genetics and Molecular Research 15 (3): gmr.15038549 
in enhancers or other distal regulatory elements that may be located in intronic and intergenic regions (Blomquist et al., 2013). Further investigation of TFs and the existence of distal regulatory elements regulating this gene could be useful to our understanding of the expression pattern observed for the KCNJ11 gene in cattle. In fact, the sum of all cis-acting factors may result in a biased ratio of the two allelic transcripts. In this sense, ASE is a quantitative trait (Tao et al., 2006), which can vary between cells, tissues, and individuals (Tycko, 2010).

Evidence of POE was also found in this experiment, with lower gene expression being observed in heterozygous individuals when the T allele was inherited from the father (CpTm $>$ CmTp). Regarding total gene expression, Tizioto et al. (2013b) found no difference in the level of gene expression among the three genotypes (CC, TT, and CT) of SNP rs379610823 using Nelore steers; however, the parental origin was not considered. Here, we analyzed only the heterozygous genotypes, in order to account for the parental origin, and different levels of total gene expression were found between reciprocal heterozygotes. Comparisons among reciprocal heterozygous and homozygous individuals were not performed because a larger sample size would be needed to apply the same methodology used by Tizioto et al. (2013b) in a parental origin study.

Tizioto et al. (2013b) found the $\mathrm{T}$ allele, which was expressed at higher levels in the present study, was associated with more tender meat. Since the T allele could lead to an increase in meat tenderness, understanding all mechanisms that affect the pathway from genotype to phenotype would be important for understanding the implications of using this polymorphism in marker-assisted selection. POE could interfere with female and male genetic values, producing deviations in additive and non-additive effects (Patten and Haig, 2008; Magee et al., 2010). Simplistically, considering only a specific trait, the F1 generation will bare more resemblance to the progenitor from which the offspring inherited the functional allele (Spencer, 2009). POE analysis of meat tenderness could not be performed here due to the small sample size.

Therefore, the KCNJ11 gene was observed to display a particular pattern of allelic expression. The effect of allelic POE in a candidate gene influencing production traits is important to better understand its expression and inheritance pattern before incorporation in marker-assisted selection. This is particularly relevant when the selection intensity is higher in one gender (Patten and Haig, 2008), which is the general practice in beef cattle breeding where males are subject to higher selective pressure. Taken together, the results of this study improve understanding of the molecular and genetic background of the KCNJ11 gene, a candidate gene affecting Nelore beef tenderness, and add to the list of ASE and POE genes in the bovine database.

\section{Conflicts of interest}

The authors declare no conflict of interest.

\section{ACKNOWLEDGMENTS}

Research supported in part by grants provided by CNPq, CAPES, and FAPESP (\#2008/03916-8; \#2012/20328 and \#2012/23638-8). L.L. Coutinho and L.C.A. Regitano were granted CNPq fellowships.

Genetics and Molecular Research 15 (3): gmr.15038549 


\section{REFERENCES}

Alekseev AE, Reyes S, Yamada S, Hodgson-Zingman DM, et al. (2010). Sarcolemmal ATP-sensitive K $(+$ ) channels control energy expenditure determining body weight. Cell Metab. 11: 58-69. http://dx.doi.org/10.1016/j.cmet.2009.11.009

Bernard C, Cassar-Malek I, Renand G and Hocquette JF (2009). Changes in muscle gene expression related to metabolism according to growth potential in young bulls. Meat Sci. 82: 205-212. http://dx.doi.org/10.1016/j.meatsci.2009.01.012

Bickhart DM and Liu GE (2013). Identification of candidate transcription factor binding sites in the cattle genome. Genomics Proteomics Bioinformatics 11: 195-198. http://dx.doi.org/10.1016/j.gpb.2012.10.004

Blomquist TM, Brown RD, Crawford EL, et al. (2013). CEBPG exhibits allele-specific expression in human bronchial epithelial cells. Gene Regul. Syst. Biol. 7: 125-138.

Garg P, Borel C and Sharp AJ (2012). Detection of parent-of-origin specific expression quantitative trait loci by cisassociation analysis of gene expression in trios. PLoS One 7: e41695. http://dx.doi.org/10.1371/journal.pone.0041695

Livak KJ and Schmittgen TD (2001). Analysis of relative gene expression data using real-time quantitative PCR and the 2(-Delta Delta C(T)) Method. Methods 25: 402-408. http://dx.doi.org/10.1006/meth.2001.1262

Lo HS, Wang Z, Hu Y, Yang HH, et al. (2003). Allelic variation in gene expression is common in the human genome. Genome Res. 13: 1855-1862.

Locke JM, Hysenaj G, Wood AR, Weedon MN, et al. (2015). Targeted allelic expression profiling in human islets identifies cis-regulatory effects for multiple variants identified by type 2 diabetes genome-wide association studies. Diabetes 64: 1484-1491. http://dx.doi.org/10.2337/db14-0957

Magee DA, Sikora KM, Berkowicz EW, Berry DP, et al. (2010). DNA sequence polymorphisms in a panel of eight candidate bovine imprinted genes and their association with performance traits in Irish Holstein-Friesian cattle. BMC Genet. 11: 93. http://dx.doi.org/10.1186/1471-2156-11-93

Marsh BB, Ringkob TP, Russell RL, Swartz DR, et al. (1987). Effects of early-postmortem glycolytic rate on beef tenderness. Meat Sci. 21: 241-248. http://dx.doi.org/10.1016/0309-1740(87)90061-1

Meyer KB, Maia AT, O'Reilly M, Teschendorff AE, et al. (2008). Allele-specific up-regulation of FGFR2 increases susceptibility to breast cancer. PLoS Biol. 6: e108. http://dx.doi.org/10.1371/journal.pbio.0060108

Muráni E, Ponsuksili S, Srikanchai T, Maak S, et al. (2009). Expression of the porcine adrenergic receptor beta 2 gene in longissimus dorsi muscle is affected by cis-regulatory DNA variation. Anim. Genet. 40: 80-89. http://dx.doi. org $/ 10.1111 / \mathrm{j} .1365-2052.2008 .01811 . \mathrm{x}$

Murani E, Ponsuksili S, Reyer H, Wittenburg D, et al. (2013). Expression variation of the porcine ADRB2 has a complex genetic background. Mol. Genet. Genomics 288: 615-625. http://dx.doi.org/10.1007/s00438-013-0776-2

Palacios R, Gazave E, Goñi J, Piedrafita G, et al. (2009). Allele-specific gene expression is widespread across the genome and biological processes. PLoS One 4: e4150. http://dx.doi.org/10.1371/journal.pone.0004150

Panebra A, Schwarb MR, Glinka CB and Liggett SB (2007). Allele-specific binding of airway nuclear extracts to polymorphic beta2-adrenergic receptor 5' sequence. Am. J. Respir. Cell Mol. Biol. 36: 654-660. http://dx.doi. org/10.1165/rcmb.2006-0394OC

Panebra A, Wang WC, Malone MM, Pitter DRG, et al. (2010). Common ADRB2 haplotypes derived from 26 polymorphic sites direct beta2-adrenergic receptor expression and regulation phenotypes. PLoS One 5: e11819. http://dx.doi. org/10.1371/journal.pone.0011819

Pastinen T and Hudson TJ (2004). Cis-acting regulatory variation in the human genome. Science 306: 647-650. http:// dx.doi.org/10.1126/science.1101659

Patten MM and Haig D (2008). Reciprocally imprinted genes and the response to selection on one sex. Genetics 179: 1389-1394. http://dx.doi.org/10.1534/genetics.107.077651

Pfaffl MW, Horgan GW and Dempfle L (2002). Relative expression software tool (REST) for group-wise comparison and statistical analysis of relative expression results in real-time PCR. Nucleic Acids Res. 30: 36e. http://dx.doi. org/10.1093/nar/30.9.e36

Ramakers C, Ruijter JM, Deprez RHL and Moorman AF (2003). Assumption-free analysis of quantitative real-time polymerase chain reaction (PCR) data. Neurosci. Lett. 339: 62-66. http://dx.doi.org/10.1016/S0304-3940(02)01423-4

Rexroad CE, 3rd, Bennett GL, Stone RT, Keele JW, et al. (2001). Comparative mapping of BTA15 and HSA11 including a region containing a QTL for meat tenderness. Mamm. Genome 12: 561-565. http://dx.doi.org/10.1007/s0033500-20028

Ruvinsky A (1999). Basics of gametic imprinting. J. Anim. Sci. 77 (Suppl 2): 228-237.

Sambrook J, Fritsch EF and Maniatis T (1989). Molecular Cloning: A Laboratory Manual. 2nd edn. Cold Spring Harbor Laboratory Press. New York.

Saupe SJ (2012). A fungal gene reinforces Mendel's laws by counteracting genetic cheating. Proc. Natl. Acad. Sci. USA 109: 11900-11901. http://dx.doi.org/10.1073/pnas.1209748109

Genetics and Molecular Research 15 (3): gmr.15038549 
Simmer F, Brinkman AB, Assenov Y, Matarese F, et al. (2012). Comparative genome-wide DNA methylation analysis of colorectal tumor and matched normal tissues. Epigenetics 7: 1355-1367. http://dx.doi.org/10.4161/epi.22562

Spencer HG (2009). Effects of genomic imprinting on quantitative traits. Genetica 136: 285-293. http://dx.doi.org/10.1007/ s10709-008-9300-8

Tao H, Cox DR and Frazer KA (2006). Allele-specific KRT1 expression is a complex trait. PLoS Genet. 2: e93. http:// dx.doi.org/10.1371/journal.pgen.0020093

Tizioto PC, Decker JE, Taylor JF, Schnabel RD, et al. (2013a). Genome scan for meat quality traits in Nelore beef cattle. Physiol. Genomics 45: 1012-1020. http://dx.doi.org/10.1152/physiolgenomics.00066.2013

Tizioto PC, Gasparin G, Souza MM, Mudadu MA, et al. (2013b). Identification of KCNJ11 as a functional candidate gene for bovine meat tenderness. Physiol. Genomics 45: 1215-1221. http://dx.doi.org/10.1152/physiolgenomics.00137.2012

Tonussi RL, Espigolan R, Gordo DG, Magalhães AF, et al. (2015). Genetic association of growth traits with carcass and meat traits in Nellore cattle. Genet. Mol. Res. 14: 18713-18719. http://dx.doi.org/10.4238/2015.December.28.20

Tuch BB, Laborde RR, Xu X, Gu J, et al. (2010). Tumor transcriptome sequencing reveals allelic expression imbalances associated with copy number alterations. PLoS One 5: e9317. http://dx.doi.org/10.1371/journal.pone.0009317

Tycko B (2010). Allele-specific DNA methylation: beyond imprinting. Hum. Mol. Genet. 19 (R2): R210-R220. http:// dx.doi.org/10.1093/hmg/ddq376

Verbeke W, Van Wezemael L, de Barcellos MD, Kügler JO, et al. (2010). European beef consumers' interest in a beef eating-quality guarantee Insights from a qualitative study in four EU countries. Appetite 54: 289-296. http://dx.doi. org/10.1016/j.appet.2009.11.013

Walker EJ, Zhang C, Castelo-Branco P, Hawkins C, et al. (2012). Monoallelic expression determines oncogenic progression and outcome in benign and malignant brain tumors. Cancer Res. 72: 636-644. http://dx.doi.org/10.1158/0008-5472. CAN-11-2266

Weaver JR, Susiarjo M and Bartolomei MS (2009). Imprinting and epigenetic changes in the early embryo. Mamm. Genome 20: 532-543. http://dx.doi.org/10.1007/s00335-009-9225-2

Wei QX, Claus R, Hielscher T, Mertens D, et al. (2013). Germline allele-specific expression of DAPK1 in chronic lymphocytic leukemia. PLoS One 8: e55261. http://dx.doi.org/10.1371/journal.pone.0055261

Weller JI and Ron M (2011). Invited review: quantitative trait nucleotide determination in the era of genomic selection. $J$. Dairy Sci. 94: 1082-1090. http://dx.doi.org/10.3168/jds.2010-3793

Wu MY, Jiang M, Zhai X, Beaudet AL, et al. (2012). An unexpected function of the Prader-Willi syndrome imprinting center in maternal imprinting in mice. PLoS One 7: e34348. http://dx.doi.org/10.1371/journal.pone.0034348

Yan H and Zhou W (2004). Allelic variations in gene expression. Curr. Opin. Oncol. 16: 39-43. http://dx.doi. org/10.1097/00001622-200401000-00008

Genetics and Molecular Research 15 (3): gmr.15038549 